Conclusion: This study has identified that within CYP initiating ETN, similar response clusters are evident to those previously identified following MTX. This commonality suggests a new framework for understanding treatment response, beyond a simple responder/non-responder analysis at a set point, which applies across multiple drugs despite different mechanisms of action and previous unfavourable treatment outcomes. Understanding both clinical factors associated with, and biological mechanisms underpinning, these clusters would aid stratified medicine in JIA.

Acknowledgements: We thank the children, young people and families involved in CLUSTER, as well as clinical staff, administrators and data management teams. Funding for CLUSTER has been provided by generous grants from the MRC, Versus Arthritis, GOSH children's charity, Olivia's vision and the NIHR Manchester and GOSH BRC schemes.

Disclosure of Interests: Stephanie Shoop-Worrall: None declared, Kimme Hyrich Speakers bureau: Abbvie, Grant/research support from: BMS, UCB, Pfizer, Lucy Wedderburn Speakers bureau: Pfizer, Grant/research support from: Abbvie, Sobi, Wendy Thomson Grant/research support from: Abbvie, Sobi, Nophar Geifman Grant/research support from: Abbvie, Sob DOI: 10.1136/annrheumdis-2021-eular.2505

\section{OP0163 COMPARATIVE ANALYSIS OF ETANERCEPT BIOSIMILAR AND ORIGINATOR USE IN CLINICAL PRACTICE: DATA FROM THE GERMAN BIKER-REGISTRY}

G. Horneff ${ }^{1}$, D. Windschall ${ }^{2}$, T. Hospach $^{3}$, S. Mrusek ${ }^{4}$, M. Rühlmann ${ }^{5}$, A. Klein ${ }^{1}$ on behalf of BIKER-Registry collaborative group. ${ }^{1}$ Sankt Augustin, Paediatrics, Sankt Augustin, Germany; ${ }^{2}$ Sendenhorst, Paediatric Rheumatology, Sendenhorst, Germany; ${ }^{3}$ Klinikum Stuttgart - Olga Hospital / Women's Hospital, Paediatrics, Stuttgart, Germany; ${ }^{4}$ Baden-Baden, Paediatric rheumatology, Baden-Baden, Germany; ${ }^{5}$ Göttingen, Paediatrics, Göttingen, Germany

Background: In 2017, 2 Etanercept biosimilars became approved. Comparative studies performed in adult patients with rheumatoid arthritis, ankylosing spondylitis or psoriasis by extrapolation led to approval for juvenile idiopathic arthritis (JIA)

Objectives: So far there is limited experience with Etanercept biosimilars in JIA: The large national data base of the BIKER-registry was used to describe experience with Etanercept biosimilars in clinical practice.

Methods: In this retrospective analysis patients exposed to ETA were identified in the German BIKER-registry and grouped into cohorts according to initiation of treatment after 2017, use of the originator and of biosimilars. The course of JADAS10, Physician global assessment VAS 0-100-mm, Parent/patient global assessment VAS 0-100-cm, Active joint count 0-71, truncated at 10, ESR and CHAQ-DI was analyzed. Descriptive statistics was used for demographic, clinical data, drug exposure, adverse events (AEs) and events of special interest (ESI).

Results: Until 31.10.2020, 2917 JIA patients were reported to have received Etanercept. Since January 12017 , in 39 centres treatment with Etanercept was started in 439 patients (377 (85.9\%) started with the originator and $62(14.1 \%)$ started a Biosimilar). Biosimilars were prescribed n 17 centres (44\%). In 12 centres $(31 \%)$, Etanercept biosimilars were used first line in 62 patients. In 17 centres (44\%), 63 patients switched for the originator to a biosimilar. 3 patients reswitched from the biosimilar to the originator. 4 patient switched from a biosimilar to the originator). 22 centres (56\%) had not prescribed a biosimilars so far. In not a single centre, initiation of a biosimilar was more frequent than of the originator.

The patients' characteristics and disease activity parameters were widely comparanble. Patients receiving biosimilar first line were slightly older at disease onset and had a longer disease duration. Patients receiving biosimilar first line had more often rheumatoid factor (RF) negative polyarthritis while extended oligoarthritis was more frequent in the originator cohort. In the switching cohort, more patients had extended oligoarthritis and fewer had RF negative polyarthritis and ERA JIA.

No difference in disease activity parameters was noted, neither at baseline, during the course of treatment nor at last observation upon treatment. A decrease of the JADAS10 indicates improvement in both groups (Figure 1). At the time of switching, $68 \%$ had JADAS minimal disease activity (MDA) and $43 \%$ were in JASDAS remission. At month 6 and 12 these numbers increased to $74 \% / 65 \%$ and $62 \% / 50 \%$.

In total, 66 adverse events $(\mathrm{AE})$ were reported in 45 patients upon biosimilar treatment.

33 patients had 1,5 patients 2,5 patients had 3 and 2 reported 4 events. Adverse event of special interest were hypersensitivity $n=1$, injection site reaction $n=1$, new onset of psoriasis $n=1$, celiac disease $n=1$, Crohn's diesease $n=1$, elevated transaminase $n=2$, depression $n=1$ and disease deterioration (arthritis flare) in $\mathrm{n}=21$. In 20 patients, the etanercept biosimilar was discontinued.
Conclusion: This analysis is the first attempt to present a large data sample on JIA patients exposed to Etanercept biosimilars. Biosimilar were used in a minority of patients and by a minority of centers although no difference in efficacy or safety was noted from our analysis. Until today, the use of the originator is by far exceeding the use of biosimilars. The prescription of a biosimilar either firs line or by switching from the originator is limited to a part of centres. Differences in efficacy between first line biosimilar users and originator users could not be observed. Also, after switching, no loss of efficacy was observed.

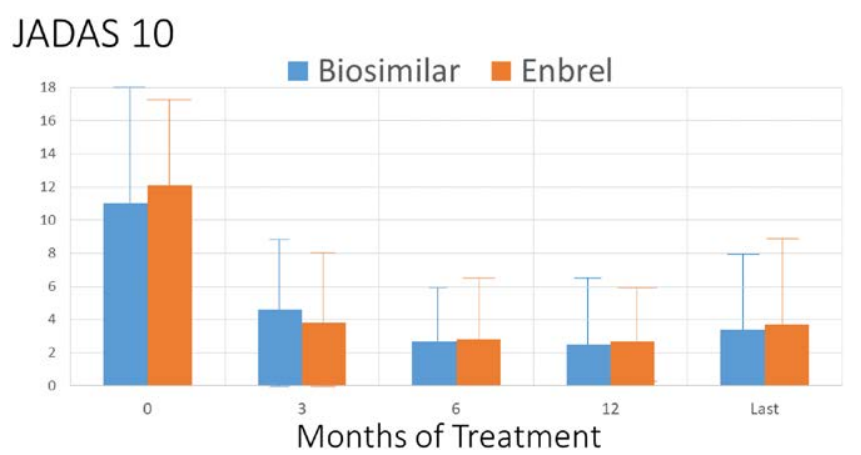

Disclosure of Interests: Gerd Horneff Speakers bureau: Pfizer, Daniel Windschall: None declared, Toni Hospach: None declared, Sonja Mrusek: None declared, Michael Rühlmann: None declared, Ariane Klein: None declared DOI: 10.1136/annrheumdis-2021-eular.1003

OP0164

LONG-TERM SAFETY OF ANAKINRA IN PATIENTS WITH SYSTEMIC JUVENILE IDIOPATHIC ARTHRITIS FROM THE PHARMACHILD REGISTRY

G. Giancane $^{1,2}$, R. Papa ${ }^{1,2}$, S. Vastert ${ }^{3}$, F. Bagnasco ${ }^{4}$, J. F. Swart ${ }^{3}$, P. Quartier ${ }^{5}$, M. Hofer ${ }^{6,7}$, J. Anton ${ }^{8}$, S. Kamphuis ${ }^{9}$, H. Sanner ${ }^{10}$, M. Glerup ${ }^{11}$, F. De Benedetti $^{12}, \mathrm{E}$. Tsitsami ${ }^{13}$, A. Remesal ${ }^{14}, \mathrm{E}$. Moreno Ruzafa ${ }^{15}, \mathrm{~J}$. De Inocencio ${ }^{16}$ C. Myrup ${ }^{17}$, C. Pallotti ${ }^{1}$, I. Koné-Paut ${ }^{18}$, K. Franck-Larsson ${ }^{19}$, H. Malmstrom ${ }^{19}$, S. Cederholm ${ }^{19}$, A. Pistorio ${ }^{4}$, N. Wulffraat ${ }^{3}$, N. Ruperto ${ }^{1} .{ }^{1}$ IRCCS Istituto Giannina Gaslini, Clinica Pediatrica e Reumatologia, Genoa, Italy; ${ }^{2}$ Università degli Studi di Genova, Dipartimento di Neuroscienze, Riabilitazione, Oftalmologia, Genetica e Scienze Materno-Infantili (DiNOGMI), Genoa, Italy; ${ }^{3}$ Wilhelmina Kinderziekenhuis, Department of Pediatric Immunology and Rheumatology, Utrecht, Netherlands; ${ }^{4}$ IRCCS Istituto Giannina Gaslini, Servizio di Epidemiologia e Biostatistica, Genoa, Italy; ${ }^{5}$ Université de Paris, Institut IMAGINE, Centre de référence national pour les Rhumatismes inflammatoires et les maladies Auto-Immunes Systémiques rares de l'Enfant (RAISE), Unité d'Immunologie, Hématologie et Rhumatologie Pédiatrique, Hôpital NeckerEnfants Malades, Assistance Publique Hôpitaux de Paris, Paris, France; ${ }^{6}$ Unité Romande d'Immuno-Rhumatologie Pediatrique, CHUV, University of Lausanne, Lausanne, Switzerland; ${ }^{7}$ Unité Romande d'Immuno-Rhumatologie Pediatrique, University Hospital of Geneva, Geneva, Switzerland; ${ }^{8}$ Hospital Sant Joan de Déu, Universitat de Barcelona, Division of Pediatric Rheumatology, Esplugues de Llobregat (Barcelona), Spain; ${ }^{9}$ Sophia Children's Hospital, Department of Paediatric Rheumatology/Department of Rheumatology, Erasmus University Medical Centre, Rotterdam, Netherlands; ${ }^{10}$ Oslo University Hospital, Dept. of Rheumatology - Norwegian National Advisory Unit on Rheumatic Diseases in Children and Adolescents, Oslo, Norway; ${ }^{11}$ Aarhus University Hospital, Pediatric Rheumatology Unit, Aarhus, Denmark; ${ }^{12}$ IRCCS Ospedale Pediatrico Bambino Gesù, Division of Rheumatology, Rome, Italy; ${ }^{13}$ Aghia Sophia Childrens Hospital, First Department of Pediatrics, University of Athens Medical School, Athens, Greece; ${ }^{14}$ University Hospital La Paz, Rheumatology Unit, Madrid, Spain; ${ }^{15}$ University Hospital Valle de Hebron, Rheumatology Unit, Barcelona, Spain; ${ }^{16} 12$ de Octubre University Hospital, Department of Pediatric Rheumatology, Madrid, Spain; ${ }^{17}$ Rigshospitalet, Pediatric Rheumatology Unit, Copenhagen, Denmark; ${ }^{18}$ National Referral Centre of Auto-Inflammatory Diseases and inflammatory amyloidosis, CEREMAIA, CHU de Bicetre, APHP, University of Paris Sud Saclay, Department of Pediatric Rheumatology, le Kremlin Bicêtre, Paris, France; ${ }^{19} \mathrm{SOBI}$, Swedish, Stockholm, Sweden

Background: Systemic juvenile idiopathic arthritis (SJIA) is characterized by extra-articular manifestations, as fever and rash, and rarely associated by a potentially lethal complication as macrophage activation syndrome (MAS). Anakinra is a recombinant human interleukin (IL)-1 receptor antagonist whose efficacy and safety profile has been studied for patients with SJIA.

Objectives: To evaluate the long-term safety profile of anakinra in patients with SJIA

Methods: Data from patients with SJIA enrolled in the Pharmachild registry before 30 September 2018 and treated with anakinra were analyzed. The study 
endpoints were the occurrence of non-serious adverse events (AEs) of at least moderate severity and serious AEs (SAEs), including macrophage activation syndrome (MAS), and the duration of anakinra treatment with reasons for discontinuation. All endpoints were analyzed overall, by 6 month-time windows and in different treatment sets represented by those patients continuously treated with anakinra for at least 12, 18 and 24 months (set-12, -18, -24, respectively). Results: 306 patients were enrolled. $46 \%, 34 \%$ and $28 \%$ of them had been treated for at least 12, 18 and 24 months, respectively. 201 AEs, mostly represented by infections, were reported for 509.3 patient-years (py) with an overall incidence rate (IR) of $39.5 / 100$ py. Among 56 SAEs (IR 11.0/100 py), (Table 1) $23.2 \%$ were infections and $19.6 \%$ MAS episodes. The IR of AEs was higher during the first 6 months of anakinra, followed by decreasing IR in the different longterm treatment sets. Treatment discontinuation occurred in $76 \%$ of patients, most in the first 6 months, due to inefficacy (43\%), remission (31\%) or AEs/intolerance (15\%). No deaths or malignancies occurred during anakinra treatment.

Table 1. Number of SAEs and incidence rates $(95 \% \mathrm{Cl})$ by overall PT decreasing order and time window in the complete set (events with a frequency $>1$ by overall SOC and $>1$ by overall PT were reported) Only time windows $<13$ months were reported in the present table.

\begin{tabular}{|c|c|c|c|c|c|c|c|}
\hline & \multirow{2}{*}{$\frac{\text { Time window }}{\mathrm{N}}$} & \multicolumn{2}{|r|}{$1-6$ months } & \multicolumn{2}{|c|}{ 7-12 months } & \multicolumn{2}{|c|}{ Overall } \\
\hline & & & 306 & & 194 & & 306 \\
\hline & Patient-time (years) & & 117.3 & & 80.2 & & 509.3 \\
\hline SOC & PT & $\mathrm{n}$ & $\begin{array}{c}\text { Rate } \\
(95 \% \mathrm{Cl})\end{array}$ & $\mathrm{n}$ & $\begin{array}{c}\text { Rate } \\
(95 \% \mathrm{Cl})\end{array}$ & $\mathrm{n}$ & $\begin{array}{c}\text { Rate } \\
(95 \% \mathrm{Cl})\end{array}$ \\
\hline All & All & 33 & $\begin{array}{c}28.1 \\
(19.1-41.5)\end{array}$ & 4 & $\begin{array}{c}5.0 \\
(1.9-13.2)\end{array}$ & 56 & $\begin{array}{c}11.0 \\
(7.9-15.2)\end{array}$ \\
\hline \multirow[t]{2}{*}{$\begin{array}{r}\text { Infections and } \\
\text { infestations }\end{array}$} & All & 7 & $\begin{array}{c}6.0 \\
(2.9-12.4)\end{array}$ & 1 & $\begin{array}{c}1.2 \\
(0.2-8.8)\end{array}$ & 13 & $\begin{array}{c}2.6 \\
(1.4-4.8)\end{array}$ \\
\hline & Pneumonia & 2 & $\begin{array}{c}1.7 \\
(0.4-6.8)\end{array}$ & 1 & $\begin{array}{c}1.2 \\
(0.2-8.8)\end{array}$ & 4 & $\begin{array}{c}0.8 \\
(0.3-2.1)\end{array}$ \\
\hline \multirow[t]{2}{*}{$\begin{array}{l}\text { Immune system } \\
\text { disorders }\end{array}$} & All & 7 & $\begin{array}{c}6.0 \\
(2.8-12.5)\end{array}$ & 1 & $\begin{array}{c}1.2 \\
(0.2-8.8)\end{array}$ & 11 & $\begin{array}{c}2.2 \\
(1.1-4.1)\end{array}$ \\
\hline & $\begin{array}{l}\text { Haemophagocytic } \\
\text { lymphohistiocytosis }\end{array}$ & 7 & $\begin{array}{c}6.0 \\
(2.8-12.5)\end{array}$ & 1 & $\begin{array}{c}1.2 \\
(0.2-8.8)\end{array}$ & 11 & $\begin{array}{c}2.2 \\
(1.1-4.1)\end{array}$ \\
\hline \multirow{3}{*}{$\begin{array}{l}\text { Injury, poisoning } \\
\text { and procedural } \\
\text { complications }\end{array}$} & All & 5 & $\begin{array}{c}4.3 \\
(1.8-10.2)\end{array}$ & - & - & 9 & $\begin{array}{c}1.8 \\
(0.9-3.4)\end{array}$ \\
\hline & $\begin{array}{l}\text { Infusion related } \\
\text { reaction }\end{array}$ & 1 & $\begin{array}{c}0.9 \\
(0.1-6.0)\end{array}$ & - & - & 2 & $\begin{array}{c}0.4 \\
(0.1-1.6)\end{array}$ \\
\hline & $\begin{array}{l}\text { Injection related } \\
\text { reaction }\end{array}$ & 4 & $\begin{array}{c}3.4 \\
(1.3-9.1)\end{array}$ & - & - & 6 & $\begin{array}{c}1.2 \\
(0.5-2.6)\end{array}$ \\
\hline $\begin{array}{l}\text { Metabolism and } \\
\text { nutrition disorders }\end{array}$ & All & 3 & $\begin{array}{c}2.6 \\
(0.8-7.9)\end{array}$ & - & - & 4 & $\begin{array}{c}0.8 \\
(0.3-2.1)\end{array}$ \\
\hline $\begin{array}{l}\text { Skin and } \\
\text { subcutaneous } \\
\text { tissue disorders }\end{array}$ & All & 3 & $\begin{array}{c}2.6 \\
(0.8-7.9)\end{array}$ & 1 & $\begin{array}{c}1.2 \\
(0.2-8.8)\end{array}$ & 4 & $\begin{array}{c}0.8 \\
(0.3-2.1)\end{array}$ \\
\hline $\begin{array}{l}\text { Blood and lymphatic } \\
\text { system disorders }\end{array}$ & All & 1 & $\begin{array}{c}0.9 \\
(0.1-6.1)\end{array}$ & - & - & 2 & $\begin{array}{c}0.4 \\
(0.1-1.6)\end{array}$ \\
\hline $\begin{array}{l}\text { General disorders } \\
\text { and administration } \\
\text { site conditions }\end{array}$ & All & 1 & $\begin{array}{c}0.9 \\
(0.1-6.1)\end{array}$ & 1 & $\begin{array}{c}1.2 \\
(0.2-8.8)\end{array}$ & 2 & $\begin{array}{c}0.4 \\
(0.1-1.6)\end{array}$ \\
\hline Investigations & All & 2 & $\begin{array}{c}1.7 \\
(0.4-6.8)\end{array}$ & - & - & 2 & $\begin{array}{c}0.4 \\
(0.1-1.6)\end{array}$ \\
\hline $\begin{array}{l}\text { Nervous system } \\
\text { disorders }\end{array}$ & All & 1 & $\begin{array}{c}0.9 \\
(0.1-6.0)\end{array}$ & - & - & 2 & $\begin{array}{c}0.4 \\
(0.1-1.6)\end{array}$ \\
\hline $\begin{array}{l}\text { Surgical and medical } \\
\text { procedures }\end{array}$ & All & 1 & $\begin{array}{c}0.9 \\
(0.1-6.0)\end{array}$ & - & - & 2 & $\begin{array}{c}0.4 \\
(0.1-1.5)\end{array}$ \\
\hline
\end{tabular}

Abbreviations: SAE, serious adverse event; SOC, system organ class; PT, preferred term, MedDRA version 21.1; $\mathrm{N}$, number of patients ever treated with anakinra during the time window irrespectively of the length of any unexposed periods; $95 \% \mathrm{Cl}, 95 \%$ Confidence Interval.

Conclusion: The results of the present study confirm the long-term safety profile of anakinra in SJIA patients and show a decreasing overall incidence rate of AEs over time.

Disclosure of Interests: Gabriella Giancane Grant/research support from: The study was funded by SOBI Swedish, Riccardo Papa Grant/research support from: The study was funded by SOBI Swedish, Sebastian Vastert Grant/ research support from: The study was funded by SOBI Swedish, Francesca Bagnasco Grant/research support from: The study was funded by SOBI Swedish, Joost F. Swart Grant/research support from: The study was funded by SOBI Swedish, Pierre Quartier Grant/research support from: The study was funded by SOBI Swedish, michael hofer Grant/research support from: The study was funded by SOBI Swedish, Jordi Anton Grant/research support from: The study was funded by SOBI Swedish, Sylvia Kamphuis Grant/research support from: The study was funded by SOBI Swedish, Helga Sanner Grant/research support from: The study was funded by SOBI Swedish, Mia Glerup Grant/research support from: The study was funded by SOBI Swedish, Fabrizio De Benedetti Grant/research support from: The study was funded by SOBI Swedish, Elena
Tsitsami Grant/research support from: The study was funded by SOBI Swedish, Agustin Remesal Grant/research support from: The study was funded by SOBI Swedish, Estefania Moreno Ruzafa Grant/research support from: The study was funded by SOBI Swedish, Jaime de Inocencio Grant/research support from: The study was funded by SOBI Swedish, Charlotte Myrup Grant/research suppor from: The study was funded by SOBI Swedish, Chiara Pallotti Grant/research support from: The study was funded by SOBI Swedish, Isabelle Koné-Paut Grant/research support from: The study was funded by SOBI Swedish, Karin Franck-Larsson Employee of: I am employee of SOBI pharmaceutical company, Hakan Malmstrom Employee of: I am employee of SOBI pharmaceutical company, Susanna Cederholm Employee of: I am employee of SOBI pharmaceutical company, Angela Pistorio Grant/research support from: The study was funded by SOBI Swedish, Nico Wulffraat Grant/research support from: The study was funded by SOBI Swedish, Nicolino Ruperto Speakers bureau: NR has received honoraria for consultancies or speaker bureaus ( $<10.000$ USD each) from the following pharmaceutical companies in the past 3 years: Ablynx, Astrazeneca-Medimmune, Bayer, Biogen, Boehringer, Bristol Myers and Squibb, Celgene, Eli-Lilly, EMD Serono, Glaxo Smith and Kline, Hoffmann-La Roche,Janssen, Merck, Novartis, Pfizer, R-Pharma, Sinergie, Sobi and UCB., Consultant of: NR has received honoraria for consultancies or speaker bureaus $(<10.000$ USD each) from the following pharmaceutical companies in the past 3 years: Ablynx Astrazeneca-Medimmune, Bayer, Biogen, Boehringer, Bristol Myers and Squibb, Celgene, Eli-Lilly, EMD Serono, Glaxo Smith and Kline, Hoffmann-La Roche,Janssen, Merck, Novartis, Pfizer, R-Pharma, Sinergie, Sobi and UCB., Grant/ research support from: The IRCCS Istituto Giannina Gaslini (IGG), where NR works as full-time public employee has received contributions (> 10.000 USD each) from the following industries in the last 3 years: BMS, Eli-Lilly, GlaxoSmithKline, F Hoffmann-La Roche, Janssen, Novartis, Pfizer, Sobi. This funding has been reinvested for the research activities of the hospital in a fully independent manner, without any commitment with third parties.

DOI: 10.1136/annrheumdis-2021-eular.1731

\section{OP0165 RISK FOR UVEITIS EVENTS AFTER WITHDRAWAL OF DISEASE MODIFYING ANTIRHEUMATIC DRUGS IN THE TREATMENT OF PATIENTS WITH EXTENDED OLIGOARTHRITIS OR RHEUMATOID FACTOR NEGATIVE POLYARTHRITIS}

J. Klotsche ${ }^{1}$, A. Klein ${ }^{2}$, M. Niewerth ${ }^{1}$, T. Kallinich ${ }^{3}$, D. Windschall ${ }^{4}$, J. P. Haas ${ }^{5}$, F. Weller-Heinemann ${ }^{6}$, T. Hospach ${ }^{7}$, F. Dressler ${ }^{8}$, K. Minden ${ }^{1}$, G. Horneff ${ }^{2}{ }^{1}$ German Rheumatism Research Centre Berlin, a Leibniz Institute, Epidemiology unit, Berlin, Germany; ${ }^{2}$ Asklepios Kinderklinik Sankt Augustin, Department of General Pediatrics, Sankt Augustin, Germany; ${ }^{3}$ Charité - Universitätsmedizin Berlin, Pediatric Pneumology and Immunology, Berlin, Germany; ${ }^{4}$ St Josef-Stift Sendenhorst, Kinder- und Jugendrheumatologie, Sendenhorst, Germany; ${ }^{5}$ Deutsches Zentrum für Kinder- und Jugendrheumatologie, Kinder- und Jugendrheumatologie, Garmisch-Partenkirchen, Germany; ${ }^{6}$ Klinikum Bremen-Mitte gGmbH, Prof.Hess-Kinderklinik, Bremen, Germany; ${ }^{7}$ Olgahospital Stuttgart, Department of Paediatric Rheumatology, Stuttgart, Germany; ${ }^{8}$ Medizinische Hochschule Hannover, Kinderklinik, Hannover, Germany

Background: Juvenile idiopathic arthritis (JIA) associated uveitis is an extra-articular manifestation of the JIA disease that may cause vision-threatening complications and an uncontrolled uveitis may even lead to blindness. Uveitis occurs in up to $20 \%$ of patients with JIA, depending on the JIA category. The majority of patients develop uveitis within the first two years after JIA symptom onset, but uveitis can continue into adulthood.

Objectives: The main objective of this study was to analyze the risk for uveitis events after discontinuing disease-modifying antirheumatic drugs (DMARD) in patients with extended oligoarthritis and rheumatoid factor (RF)-negative polyarthritis.

Methods: Data of the two ongoing multicenter biologic registers: German Biologics in Pediatric Rheumatology (BiKeR) and the Juvenile arthritis Methotrexate/ Biologics long-term Observation (JuMBO) were used to analyze the adverseevent $(A E)$ and events of special interest $(E S I)$ reports about uveitis events during treatment and after discontinuation of DMARDs. Biker started recruitment of children and adolescent patients with JIA exposed to biological (b) or conventional (cs) DMARD's in 2001. The patients were further followed in JuMBO after reaching the age of 18 or transitioning to an adult rheumatologist. Disease characteristics, treatment data, AE's and ESI's were reported by the pediatric or adults rheumatologist, respectively.

Results: A total of 2,041 patients with RF-negative polyarthritis $(n=1,280)$ or extended oligoarthritis $(n=761)$ were included into the analyses. The mean follow-up of this study was 7.6 years (SD 5.3). About half of the patients were enrolled in BiKeR with start of etanercept (1,137, 55.7\%), followed by 635 $(31.1 \%)$ patients with start of methotrexate (MTX) monotherapy or adalimumab (ADA, $n=198,9.7 \%)$. A history of uveitis was reported for $238(11.7 \%)$ patients 